\title{
DIREITO E INTERDISCIPLINARIDADE: AS MUDANÇAS NECESSÁRIAS NA PRÁTICA EDUCATIVA NA SOCIEDADE DE RISCO
}

\author{
LAW AND INTERDISCIPLINARITY: THE NECESSARY CHANGES IN EDUCATIONAL \\ PRACTICE IN THE RISK SOCIETY
}

\author{
LEY E INTERDISCIPLINARIDAD: LOS CAMBIOS NECESARIOS EN LA PRÁCTICA \\ EDUCATIVA EN LA SOCIEDAD DE RIESGOS
}

Alboni Marisa Dudeque Pianovski Vieira E-mail: alboni@alboni.com

Amanda Ferraz da Silveira E-mail: aferraz.silveira@gmail.com Pontifícia Universidade Católica do Paraná - PUCPR

\begin{abstract}
RESUMO
O advento da sociedade industrial e a expansão do modo de produção capitalista, baseados na apropriação da natureza e do trabalho, acabaram por encaminhar a humanidade para a sociedade de risco. Diante do contexto histórico de surgimento do modo de produção capitalista e da consolidação dos Estados nacionais, o Estado revelase um agente essencial para a continuidade do desenvolvimento do sistema capitalista. Como base da estrutura de organização e funcionamento do Estado, o direito também está incluído no conjunto de elementos mantenedores da construção do risco. No entanto, diante deste cenário irrefutável, como a prática educativa da ciência do direito tem se comportado e reproduzido diante da crise socioambiental? O objetivo deste trabalho é analisar a necessidade de uma prática educativa interdisciplinar do Direito Socioambiental em face da sociedade de risco e da crise ecológica. Como metodologia, faz-se uso da combinação dos métodos de abordagem dialético e indutivo, dos métodos de procedimento monográfico e comparativo, e das técnicas de pesquisa bibliográfica e documental. Conclui-se que as modificações necessárias no Direito perpassam, necessariamente, pelo diálogo com outras disciplinas e devem abarcar também a prática educativa no seu ensino.
\end{abstract}

PALAVRAS-CHAVE: Sociedade de Risco. Prática pedagógica. Interdisciplinaridade.

\begin{abstract}
The advent of industrial society and the expansion of the capitalist mode of production, based on the appropriation of nature and work, ended up directing humanity towards a risk society. In view of the historical context of the emergence of the capitalist mode of production and the consolidation of national states, the state proves to be an essential agent for the continued development of the capitalist system. As a basis for the structure of organization and functioning of the State, the law is also included in the set of elements that maintain the construction of risk. However, in view of this irrefutable scenario, how has the educational practice of the science of law behaved and reproduced in the face of the socio-environmental crisis? The objective of this work is to analyze the need for an interdisciplinary educational practice of Socio-Environmental Law in face of the risk society and ecological crisis. As a methodology, a combination of dialectical and inductive methods, monographic and comparative procedure methods, and bibliographic and documentary research techniques is used. It is concluded that the necessary changes in law necessarily involve dialogue with other disciplines and should also include their educational practice in their teaching.
\end{abstract}

KEYWORDS: Risk Society. Pedagogical practice. Interdisciplinarity. 


\section{RESUMEN}

El advenimiento de la sociedade industrial y la expansión del modo de producción capitalista, basado en la apropriación de la naturaleza y el trabajo, terminaron llevando a la humanidade hacia una sociedade de riesgo. En vista del contexto histórico del surgimento del modo de producción capitalista y la consolidación de los estados nacionales, el estado demuestra ser un agente essencial para el desarrollo contínuo del sistema capitalista. Como base para la estrutura de organización y funcionamento del Estado, la ley también se incluye en el conjunto de elementos que mantienen la construcción del riesgo. Sin embargo, en vista de este escenario irrefutable, ¿cómo se ha comportado y reproducido la práctica educativa de la ciencia del derecho ante la crisis socioambiental? El objetivo de este trabajo es analizar la necesidad de una práctica educativa interdisciplinaria del Derecho Socioambiental frente a la sociedad de riesgo y la crisis ecológica. Como metodología, se utiliza una combinación de métodos dialécticos e inductivos, métodos de procedimientos monográficos y comparativos, y técnicas de investigación bibliográfica y documental. Se concluye que los cambios necesarios en la Ley necesariamente implican el diálogo con otras disciplinas y también deben abarcar la práctica educativa en su enseñanza.

PALABRAS-CLAVE: Sociedad de riesgo. Práctica pedagógica. Interdisciplinariedad.

\section{INTRODUÇÃO}

O advento da sociedade industrial e a expansão do modo de produção capitalista, baseados na apropriação da natureza e do trabalho, acabaram por encaminhar a humanidade para a sociedade de risco (BECK, 2010). Nesse contexto, a produção de um conhecimento científico é realizada a partir de necessidades do mercado, utilizadas para a justificação de valores determinados. A ciência vincula-se à tecnologia, que se liga à indústria, em uma relação de retroalimentação que se volta às necessidades do sistema de produção capitalista. Nesse sentido, a ciência, ao mesmo tempo em que é responsável pela criação e pelo desenvolvimento da energia nuclear e da biotecnologia, também é o ator capaz de apurar e tentar mensurar os riscos decorrentes das atividades da sociedade.

Diante do contexto histórico de surgimento do modo de produção capitalista e da consolidação dos Estados nacionais, o Estado revela-se um agente essencial para a continuidade do desenvolvimento do sistema capitalista. Como base da estrutura de organização e funcionamento do Estado, o direito também está incluído no conjunto de elementos mantenedores da construção do risco. O uso e a exploração inescrupulosos da força de trabalho e da natureza pelas estruturas estatais, que a ciência tentou justificar ou maquiar, propiciaram a expansão do modo de produção capitalista pelo mundo e acarretaram a crise ecológica.

Ao mesmo tempo em que mantenedor do sistema, o direito moderno estatal, por meio de políticas públicas e do ordenamento jurídico, ganha relevância ao ser alçado como agente que pode evitar ou mitigar efeitos e consequências de catástrofes decorrentes da crise ecológica. Assim, o Direito torna-se uma ferramenta importante de ação e a sua ciência e principalmente seu ensino ganham especial relevância. No entanto, diante desse cenário irrefutável, como a 
prática educativa da Ciência do Direito tem se comportado e reproduzido diante da crise socioambiental? De quais recursos o ensino do Direito pode se utilizar para melhorar a compreensão da crise socioambiental do capitalismo?

O objetivo desse trabalho é analisar a necessidade de uma prática educativa interdisciplinar do Direito Socioambiental em face da sociedade de risco e da crise ecológica. Como metodologia, faz-se uso da combinação dos métodos de abordagem dialético e indutivo, dos métodos de procedimento monográfico e comparativo, e das técnicas de pesquisa bibliográfica e documental. Em um primeiro momento, apontam-se as características da sociedade de risco. Após, são tecidas considerações sobre o direito ambiental e a crise ecológica e, nesse contexto, o direito socioambiental. Por fim, analisa-se a necessidade de uma prática educativa interdisciplinar do Direito Socioambiental, de forma a aproximar o ensino do Direito à materialidade.

\section{A SOCIEDADE DE RISCO}

Como uma teoria social, o risco é o elemento essencial à compreensão dos conceitos e dos processos da sociedade industrial, pois se configuram como ameaças decorrentes de decisões tomadas durante o processo de expansão industrial. Nesse ponto reside a diferença entre risco e perigo. O primeiro, conforme apontado, é intrínseco ao desenvolvimento industrial (BECK, 2010). É marcado pela incerteza, pela probabilidade de ocorrência e pelo resultado da tomada de decisões presentes que se projetam no futuro. O segundo, por sua vez, é uma ameaça "[...] vinculada a fatores externos com causas naturais e metafísicas" (FERREIRA, 2016, p. 113).

Considerando o risco como o principal elemento da sociedade industrial, a natureza deste é responsável por delimitar dois momentos dessa sociedade. A primeira modernidade, consistindo em um momento inicial da sociedade industrial, é caracterizada pela natureza previsível e calculável dos riscos. Sendo previsíveis e calculáveis, os riscos são limitados temporal e espacialmente, pois estavam vinculados ao seu local de produção.

Ao mesmo tempo em que a sociedade industrial se desenvolve científica e tecnologicamente para conter efeitos negativos derivados de suas próprias decisões tomadas no curso dos processos de expansão, conseguiu se direcionar para um estado de autoeliminação potencial, impulsionado, principalmente, pelo crescimento econômico e pelo progresso técnicocientífico (FERREIRA, 2016). Estes mesmos fatores foram responsáveis pela origem da 
sociedade de risco, que "[...] se origina quando os riscos oriundos de ações e decisões humanas rompem os pilares de certeza estabelecidos pela sociedade industrial, minando, como consequência, seus padrões de segurança" (FERREIRA, 2016, p. 116). Nessa perspectiva, lembrando Beck (2010), a violação do pacto de segurança é concomitante à violação do pacto de consenso (FERREIRA, 2016).

Os riscos, então, passam a ameaçar "[...] a vida no planeta, sob todas as suas formas" (BECK, 2010, p. 26). Assim, assumindo caráter imprevisível e incalculável, com efeitos transtemporais e transfronteiriços, o risco constitui elemento da segunda modernidade ou sociedade de risco. Esses riscos são decorrentes, principalmente, do desenvolvimento biotecnológico (armas biológicas e manipulação genética) e da energia nuclear (armas e acidentes) e escapam totalmente da percepção humana imediata (BECK, 2010). Dessa forma, o risco é democrático, pois paira sobre todos indistintamente, mas impossível de ser distribuído igualmente e/ou de maneira aceitável aos sujeitos que arcarão com as consequências de sua concretização (FERREIRA, 2016). Ou seja, ainda que a ameaça paire sobre todos, as consequências da concretização dos riscos serão suportadas de forma desigual pelas pessoas. Nesse sentido, há grupos de pessoas tidas como mais vulneráveis na sociedade de risco. Essa vulnerabilidade decorre do conjunto de condições socioculturais de cada grupo e não está, necessariamente, atrelada à renda ou ao poder aquisitivo.

Se na primeira modernidade os riscos foram considerados como necessários ao progresso, na segunda modernidade não podem ser mais aceitos como aspectos inevitáveis da modernização (FERREIRA, 2016). Os riscos, embora detenham um potencial catastrófico, são ignorados pela sociedade em uma atividade orquestrada entre várias instituições: Estado, mídia, conglomerados capitalistas e ciência. Na segunda modernidade, há produção de um conhecimento científico a partir de necessidades do mercado, utilizadas para " [...] fundamentar interesses específicos de um conjunto de valores determinado" (FERREIRA, 2016, p. 126).

A ciência atrela-se à tecnologia, que se vincula à indústria, em uma relação de retroalimentação que se volta às necessidades do sistema de produção capitalista e abandona valores sociais, morais e ecológicos. Segue padrões lineares e deterministas, que refletem a racionalidade mecanicista moderna e que são incapazes de abarcar à complexidade dos riscos gerados. Nesse sentido, a ciência ao mesmo tempo em que é responsável pela criação e pelo desenvolvimento da energia nuclear e da biotecnologia, também é o ator capaz de apurar e tentar mensurar os riscos decorrentes dessa atividade. Assim, vemos que "[...] os mesmos 
valores que alicerçam a formação de uma sociedade de risco têm também penetrado o campo de atuação da ciência" e, em consequência, extirpado o caráter de neutralidade dela, que passou a atuar a partir de "[...] interesses essencialmente mercadológicos" (FERREIRA, 2016, p. 125).

No contexto de apuração dos riscos pela ciência e pelas instituições, surgem os conceitos dos padrões de segurança, que restam falidos; da irresponsabilidade organizada; e da construção institucional do risco (FERREIRA, 2016). Esses últimos decorrentes da ação harmônica entre os atores envolvidos para dissimulação dos riscos para apresentação à sociedade e perpetuidade da reprodução do capital, base do sistema econômico hegemônico.

Nessa linha, os meios de comunicação de massa detêm atividade relevante, pois são responsáveis pela transmissão de informações à sociedade (FERREIRA, 2016). Da mesma forma, os interesses do mercado passaram a pautar as atividades das instituições, principalmente do Estado, que ainda que tenha assumido o compromisso de garantir o bem das sociedades e do meio ambiente constitucionalmente, passa a agir em favor dos interesses do sistema capitalista, mascarando e por vezes inviabilizando o cumprimento de medidas de preservação e segurança (FERREIRA, 2016).

O Estado, nesse contexto, perdeu parte de seu poder diante do controle do mercado financeiro global das corporações. A globalização possibilita que, a qualquer sinal de instabilidade ou de medida contrária à maximização das margens de lucro, os investimentos e o capital sejam retirados imediatamente de Estados, o que acarreta instabilidade financeira e suscetibilidade às vontades das corporações (CAPRA, 2006). Segundo Mandel, as principais funções do Estado no sistema capitalista são:

1. Criar as condições gerais de produção que não podem ser asseguradas pelas atividades privadas dos membros da classe dominante;

2. Reprimir qualquer ameaça das classes dominadas ou de frações particulares das classes dominantes ao modo de produção corrente através do Exército, da polícia, do sistema judiciário e penitenciário;

3. Integrar as classes dominadas, garantir que a ideologia da sociedade continue sendo a da classe dominante e, em consequência, que as classes exploradas aceitem sua própria exploração sem o exercício direto da repressão contra elas (porque acreditam que isso é inevitável, ou que é 'dos males o menor', ou a 'vontade suprema', ou porque nem percebem a exploração). (MANDEL, 1982, p. 333-334).

No percurso histórico de surgimento do modo de produção capitalista e da consolidação dos Estados nacionais, percebe-se a necessária ação do Estado à manutenção desse modo de 
produção. O Estado é, portanto, um agente essencial à continuidade do desenvolvimento do sistema capitalista (WOOD, 2014).

Como base da estrutura de organização e funcionamento estatal, o Direito também está incluído no conjunto de elementos mantenedores da construção do risco. É o elemento de reforço da irresponsabilidade organizada, visto que opera pela produção de normas que autorizam ações produtoras dos riscos, conferindo uma legitimidade e regularidade, com a manutenção do status quo; ou que permanecem ineficazes dentro do ordenamento jurídico, produzindo efeitos contrários aos que se propõem (FERREIRA, 2016). Apresentado tradicionalmente como limitador da atividade do Estado para promoção dos chamados direitos e garantias individuais, o Direito moderno estatal, em verdade, legitima a atividade violenta e ideológica do Estado, de forma a manter a sociedade informalmente estratificada e justificar a desigualdade e a injustiça social.

As relações entre Direito, Estado e mercado são complexas, mas só o Estado, por meio do Direito e nele baseado, pode exercer um controle social tido como "legítimo" à manutenção do sistema capitalista e justificação das desigualdades por ele produzidas e mantidas (WOOD, 2014). Portanto, serve o Direito para referendar e introduzir, como orientação da sociedade, a lógica de mercado da liberdade e livre iniciativa, dissimulando e desvirtuando as situações de risco.

\section{A CRISE ECOLÓGICA E O DIREITO}

O Estado, desde sua origem, trata da manutenção das condições necessárias ao avanço do sistema de produção hegemônico, construindo e assumindo um caráter privatista e patrimonialista que se reflete em suas estruturas. Esse caráter pode ser verificado nos conflitos entre direitos coletivos e/ou difusos e propriedade privada, nos quais acaba prevalecendo a proteção ao direito à propriedade privada, posto e encarado como universal e natural (SOUZA FILHO, 2003). Ao assumir as necessidades do sistema de produção capitalista, as estruturas estatais favorecem o esgotamento das duas forças fundamentais do mundo: a força de trabalho e a natureza (SOUZA FILHO, 2016). Partindo da noção moderna de progresso, o desenvolvimento é cunhado como objetivo da sociedade que continua a transformar a natureza em mercadoria, visto que se achava que os recursos naturais eram inesgotáveis (SILVEIRA, 2019). 


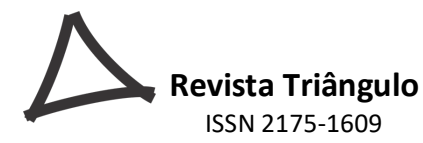

No entanto, a maior parte dos recursos retirados da natureza tem data para acabar. O uso e a exploração inescrupulosos, que a ciência tentou justificar ou maquiar, propiciaram a expansão do modo de produção capitalista pelo mundo e o faz se alimentar de crises (MESZÁROS, 2011). Por essa razão, não há planejamento e ou gestão pensada e responsável a respeito do uso e da exploração, além daquela que se relaciona com aumentar as formas de se maximizar o lucro. A crise ecológica dá-se em razão da inexistência de planejamento para o sistema de produção capitalista, que se alimenta da natureza e não assume as dinâmicas ecossociais (LÖWY, 2005) necessárias para que exista uma recomposição. As ações individuais e sem planejamento fazem com que a natureza não consiga repor o que o capital individualmente retira, o que gera uma falha metabólica insuperável (FOSTER, 2011). Ou seja, não são necessidades humanas baseadas na sobrevivência que produzem a falha metabólica, mas a necessidade do capital de continuar sua retroalimentação e reprodução.

A crise ecológica é global, é a dimensão de uma sociedade fundada em riscos assumidos (BECK, 2002). Os riscos decorrentes das atividades humanas modernas no planeta, imprevisíveis e incalculáveis, são produzidos a partir de decisões em relação ao meio ambiente e possuem dimensões "[...] globais, transfronteiriças e potencialmente catastróficas que se projetam no futuro através de decisões presentes" (FERREIRA, 2016, p. 151). Essa crise compromete toda a biodiversidade existente, incluindo a própria humanidade, e tem uma face também social iniciada na expulsão daqueles que da terra viviam e tiravam sustento, transformando o trabalho em um conceito atrelado à produção de mercadoria para a reprodução do capital, que se confunde com a própria origem do capitalismo (WOOD, 2000).

Ainda que com diferentes atores, a mesma dinâmica analisada por Marx e outros, que possibilitou o surgimento do capitalismo na Europa, foi reproduzida na América Latina, com o mesmo fetichismo pela mercadoria e absorta pelo progresso (TIBLE, 2003). Os povos e as comunidades latino-americanas, por não produzirem excedentes e mercadorias, foram excluídos da lógica progressista do sistema capitalista, condenados como atrasados, primitivos e entraves ao progresso. Ao avançar sobre seus territórios, o sistema de produção capitalista corrói os tecidos sociais que os mantêm em comunidade e em seus locais capazes de produzir para sua subsistência física e cultural (SOUZA FILHO, 2016). 
A destruição da natureza é própria da forma moderna de organização da produção e da política. No entanto, para as sociedades não capitalistas ${ }^{1}$, a natureza é algo vivo, que participa da cultura e esta dela participa, em uma mútua construção e existência (DIEGUES, 1999-2000). Desde as décadas de 1960 e 1970, a partir da crítica à destruição da natureza pelo capitalismo nos debates da Conferência das Nações Unidas sobre o Meio Ambiente, o planeta passa a viver no limite do uso daquilo que chamou de "recursos" naturais. Surgiram correntes a respeito de como conciliar o crescimento econômico com a preservação da natureza (DIEGUES, 2001). A corrente do ecodesenvolvimento dispunha que, ao mesmo tempo em que se aborda o uso adequado da natureza, fala-se em divisão da riqueza e da educação voltada ao uso adequado dos recursos naturais. Assim, seria possível obter uma gestão ética e participativa dos recursos naturais. O desenvolvimento sustentável, por sua vez, seguiu-se ao ecodesenvolvimento e compreendeu que a sociedade controlaria seus modos de produção, para que o uso não extrapolasse a capacidade e os ciclos da natureza e não comprometesse as reservas para as futuras gerações.

Essa expansão do sistema de produção capitalista, mediante o aprofundamento da violência sobre os povos e a natureza, e a diversificação da produção, possibilitada pelo avanço da ciência e da técnica, culminaram em uma crise socioambiental de dimensões globais. Os impactos decorrentes das atividades humanas dentro do sistema de produção são tão profundos que importaram em uma nova época geológica denominada de capitaloceno ${ }^{2}$. Essa crise também pode ser chamada de socioambiental, pois a crise social está ligada à crise da natureza (SOUZA FILHO, 2016). É “[...] um problema com uma dimensão intergeracional e interespécies" (PERALTA, 2015, p. 121), que põe em risco a própria teia da vida (CAPRA, 2006). A degradação ecológica em andamento “[...] é um problema de caráter ético que afeta de maneira dramática o bem-estar da vida no planeta, e que, consequentemente, tem uma transcendência política, social e econômica para a humanidade" (PERALTA, 2015, p. 121).

Políticas públicas e ordenamento jurídico dos Estados ganham relevância ao serem alçados como agentes que podem evitar ou mitigar efeitos e consequências de catástrofes

\footnotetext{
Opta-se por utilizar a expressão "não capitalistas" em lugar do "não modernas" para evitar concepções de "atrasadas" e "primitivas", considerando que a crítica é ao sistema de produção capitalista, que tem sua expansão com e na modernidade.

"Nesse trabalho, ainda que seja denominado também de "antropoceno", opta-se pela expressão "capitaloceno", por se entender que não é a presença humana a responsável pelos impactos e mudanças, mas o sistema de produção capitalista. Adotar a expressão "antropoceno" seria uniformizar as diversas formas de relação com a natureza e que diferem, em essência, da relação construída pela modernidade e pelo sistema de produção mundializado.
} 
decorrentes da crise ecológica. Assim, o Direito torna-se uma ferramenta importante de ação. No entanto, diante desse cenário irrefutável, como o Direito moderno tem se comportado diante da crise socioambiental?

O Direito moderno, fruto dos Estados nacionais, compartimentalizou-se e fragmentou-se em áreas de acordo com seus objetos e objetivos. Nesse sentido, o Direito Ambiental encarregou-se de fazer a sistematização e a "[...] articulação da legislação, doutrina e jurisprudência concernentes aos elementos que integram o meio ambiente. Procura evitar o isolamento dos temas ambientais e sua abordagem antagônica" (MACHADO, 2015, p. 50). Em suma, há quatro propostas do sistema de produção capitalista para encarar a crise ambiental (SOUZA FILHO, 2016): criação de espaços territoriais especialmente protegidos; indução de comportamentos; internalização dos "custos ambientais" da produção; e controle de processos e imposição de restrições a atividades humanas.

A criação de espaços territoriais especialmente protegidos, em um primeiro momento, afronta o próprio sistema ao retirar a terra do espaço de comercialização. No entanto, não raramente a criação de redomas verdes viola direitos de povos e comunidades tradicionais ao não permitir que continuem a viver em seus territórios (CALEIRO; SOUZA FILHO, 2018), consistindo em uma tentativa de recriar uma natureza intocada, fruto de um mito moderno (DIEGUES, 2001), acabando por aumentar o distanciamento entre ser humano e natureza.

Em relação à indução de comportamentos, esta tem dependido de ações do próprio Estado em atenção ao mercado, concretizadas em geral por políticas públicas e/ou incentivos fiscais, todos com reflexos econômicos e de fomento ao mercado. Em sua maior parte, as discussões encontram obstáculo no pouco rigor técnico e nas tentativas de atendimento aos interesses políticos e econômicos (SILVA, 2012), pois há um cuidado em não afetar diretamente algumas atividades centrais do atual meio de produção, como a exploração mineral e de hidrocarbonetos. A necessidade de discussão de medidas de mitigação que não possam afetar o atual sistema de produção é analisada, em relação ao clima, em Cornetta (2012). Haveria ainda indicações de que a tributação verde, na prática, apenas tem sido realizada para o incremento arrecadatório, sendo a questão ambiental um mero pretexto para tanto (SILVA, 2012).

A internalização dos “custos ambientais" da produção indica uma transferência dos custos ao destinatário final da mercadoria ou produto. Segundo a proposta, haveria uma precificação do dano de forma a se incluir no preço o "valor real da produção". Essa proposta, contudo, aparenta não evitar que seja realizado o dano, mas busca uma esperança de diminuição do 
consumo de determinada mercadoria por seu preço elevado em razão da dimensão do dano causado (TUPIASSU, 2006).

Pelo controle de processos e imposição de restrições, o Estado pode articular e ordenar as atividades econômicas exercidas pela livre iniciativa. Pela exigência de estudos de impacto para concessão de licenças à execução de atividades pode se ter uma "dimensão do dano" à natureza e a sua valoração. Se muito grande ou significativa de acordo com certos critérios, a atividade somente poderia ser executada com o cumprimento de certas condições, como a instalação de medidas de mitigação de impactos. Por vezes, a atividade é executada com a promessa de cumprimento das medidas e, não raras vezes, sequer são executadas na totalidade. Observado dano não "previsto", o argumento geralmente utilizado pelos agentes causadores dos danos é "estarem dentro da lei".

Ainda que a cada instrumento acima indicado caiba um estudo profundo e singular, é importante se considerar o seu conjunto para a análise do sistema previsto pelas políticas nacionais de proteção à natureza. Como exemplo, no caso brasileiro, essa política declaradamente objetiva “[...] a preservação, melhoria e recuperação da qualidade ambiental propícia à vida, visando assegurar, no País, condições ao desenvolvimento socioeconômico, aos interesses da segurança nacional e à proteção da dignidade da vida humana" (BRASIL, 1981, art. $2^{\text {o }}$ - grifos nossos). Esse conjunto tem se mostrado como importante ferramenta a serviço da reprodução do capital.

\section{A NECESSIDADE DE UMA ABORDAGEM INTERDISCIPLINAR CRÍTICA NO ENSINO DO DIREITO SOCIOAMBIENTAL}

Antes de serem iniciadas as considerações sobre Direito Ambiental e Direito Socioambiental, necessário se faz pensar a respeito do que é o Direito e, consequentemente, do que se ocupa a ciência jurídica, e como é apresentado a partir das estruturas e dos elementos da sociedade de risco. Estudantes de graduação iniciam o curso em universidades confundindo, em geral, o direito com o positivismo jurídico ou com o direito estatal. Em verdade, esta é uma das concepções do que é o direito e nela não se esgota. O direito possui relações com a justiça e, mais uma vez, não se confunde com a aplicação da justiça pelo Estado pelo Poder Judiciário, no caso brasileiro. O direito estatal, por vezes, carrega o direito e o antidireito (LYRA FILHO, 
2012), ou seja, as leis, embora sejam consideradas válidas à medida que atendem aos requisitos exigidos pelo sistema jurídico, carregam muitas vezes disposições injustas.

Da mesma forma, o direito tem ligações com a moral. O pensamento científico moderno, em busca de um conhecimento neutro e imparcial, buscou analisar o direito e a moral. Para o jusnaturalismo, o direito tem origem em um padrão metafísico, ou seja, em proposições apriorísticas transcendentais (CALEIRO; WANDSCHEER, 2016). Ou seja, há um direito natural que é imutável e constante, que se sobrepõe ao direito posto. Em contraposição à metafísica, encontra-se o positivismo, que busca partir do estudo de um objeto concreto para uma leitura descritiva e exata, cuja origem está na realidade das coisas. Uma teoria pura do direito foi construída por Kelsen (2009), segundo a qual o direito nunca é neutro, mas, sim, a ciência do direito. E o objeto da ciência do direito, para Kelsen, é o direito positivo do Estado. Após, a separabilidade entre direito e moral continuou objeto de interesse de Hart (2011), Dworkin (2014) e outros, dentro do positivismo na Teoria do Direito.

Independentemente das compreensões acima, a ciência do direito é construída a partir das concepções da modernidade e, por isso, é formulada e reproduzida de forma compartimentada, como se a vida e a sociedade fossem gavetas separadas, organizadas e estanques, as quais se podem abrir e fazer uso quando forem úteis. Quando não o forem, basta mantê-las na forma como estão. E é dessa forma que a ciência do direito é repassada no ensino superior. Embora os currículos de maneira geral devam obedecer às diretrizes curriculares básicas dispostas pelo Ministério da Educação, o que se observa é a reprodução e validação do direito estatal e suas estruturas (WOOD, 2014; WALZER, 1999) e, via de consequência, do próprio sistema de produção capitalista. Esse é um direito posterior, ou seja, origina-se a partir das relações já existentes na sociedade e que, por essa razão, acabam positivadas em lei. O direito é um fato social e o direito moderno tem suas fontes nas relações sociais privadas, mas ignora as coletividades e suas expressões.

Como uma de suas compartimentalizações, o direito ambiental é a seção do direito público que trata das limitações ao exercício do direito real de propriedade, em sua concepção de origem. No entanto, essa concepção mostra-se desconexa com a realidade material dos contextos socioambientais existentes na América Latina e, especialmente, no Brasil. Evidenciada na segunda metade do século XX, a crise ecológica apresenta a completa falha dos sistemas e regulações dos riscos existentes, o que demanda que repensemos nossa própria 
condição de seres humanos e sociedade, em uma profunda mudança se desejarmos continuar a viver.

Essa reflexão e transformação deve perpassar pela ciência do direito e a formação nas universidades, para que possa atingir a prática do Poder Judiciário, legislação e políticas públicas e, em alguma medida, mitigar os efeitos da crise ecológica. Usamos formação nesse contexto no sentido atribuído por Paulo Freire (2002, p. 10), para o qual, “[...] formar é muito mais do que puramente treinar o educando no desempenho de destrezas" (grifos nossos). Assim, a prática educativa do processo de formação deve ser voltada à construção da autonomia e da liberdade.

Nesse sentido, essa prática educativa da ciência jurídica deve ser crítica à medida que parte da realidade e do próprio direito moderno para conhecer suas falhas e críticas. Para tanto, é necessário o abandono de uma educação "bancária" (FREIRE, 2002), que é comum nas ciências consideradas "humanas" e, especialmente, no Direito, para uma educação construída de forma dialógica, ou seja, a partir da interação com as diferenças viventes no mundo, em busca de diferentes pontos e formas de abordagem.

As diretrizes básicas da graduação em Direito formuladas pelo Ministério da Educação dispõem um perfil desejado do graduando. Para atingi-lo:

[...] o curso de graduação em Direito deverá assegurar, no perfil do graduando, sólida formação geral, humanística, capacidade de análise, domínio de conceitos e da terminologia jurídica, capacidade de argumentação, interpretação e valorização dos fenômenos jurídicos e sociais, além do domínio das formas consensuais de composição de conflitos, aliado a uma postura reflexiva e de visão crítica que fomente a capacidade e a aptidão para a aprendizagem, autônoma e dinâmica, indispensável ao exercício do direito, à prestação da justiça e ao desenvolvimento da cidadania. (BRASIL, 2018, art. $3^{\circ}$ ).

Sobre os conteúdos, as diretrizes preveem disciplinas propedêuticas. Porém, a maior parte do curso é voltada ao aprendizado e ao treinamento para a prática do direito estatal moderno que, em última análise, serve aos propósitos da reprodução do capital e é uma importante ferramenta para a irresponsabilidade organizada da sociedade de risco:

I - Formação geral, que tem por objetivo oferecer ao graduando os elementos fundamentais do Direito, em diálogo com as demais expressões do conhecimento filosófico e humanístico, das ciências sociais e das novas tecnologias da informação, abrangendo estudos que, em atenção ao PPC, envolvam saberes de outras áreas 
formativas, tais como: Antropologia, Ciência Política, Economia, Ética, Filosofia, História, Psicologia e Sociologia;

II - Formação técnico-jurídica, que abrange, além do enfoque dogmático, o conhecimento e a aplicação, e a aplicação, observadas as peculiaridades dos diversos ramos do Direito, de qualquer natureza, estudados sistematicamente e contextualizados segundo a sua evolução e aplicação às mudanças sociais, econômicas, políticas e culturais do Brasil e suas relações internacionais, incluindose, necessariamente, dentre outros condizentes com o PPC, conteúdos essenciais referentes às áreas de Teoria do Direito, Direito Constitucional, Direito Administrativo, Direito Tributário, Direito Penal, Direito Civil, Direito Empresarial, Direito do Trabalho, Direito Internacional, Direito Processual; Direito Previdenciário, Formas Consensuais de Solução de Conflitos; e

III - Formação prático-profissional, que objetiva a integração entre a prática e os conteúdos teóricos desenvolvidos nas demais perspectivas formativas, especialmente nas atividades relacionadas com a prática jurídica e o TC. (BRASIL, 2018, art. $5^{\circ}$ ).

Os conteúdos de formação técnico-jurídica e de formação prático-profissional são voltados especificamente ao sistema jurídico brasileiro e à sua aplicação dentro da legislação estatal e, em caso de litígios, do Poder Judiciário. Em relação ao direito ambiental, não seria esperado outro tipo de abordagem senão aquela voltada à reprodução da prática jurídica estatal.

As recém-aprovadas Diretrizes Curriculares do curso de Direito preveem, ainda, no art. $5^{\circ}, \S 3^{\circ}$, que

Tendo em vista a diversificação curricular, as IES poderão introduzir no PPC conteúdos e componentes curriculares visando desenvolver conhecimentos de importância regional, nacional e internacional, bem como definir ênfases em determinado(s) campo(s) do Direito e articular novas competências e saberes necessários aos novos desafios que se apresentem ao mundo do Direito, tais como: Direito Ambiental, [...]. (BRASIL, 2018, art. 5).

A inserção do direito ambiental na matriz curricular do curso, portanto, é facultativa, ficando a cargo das IES introduzi-la ou não no Projeto Pedagógico do Curso. Em alguns currículos, o direito ambiental enquanto disciplina tem sido substituído pelo direito socioambiental. Essa disciplina, ou área do Direito, vai além da simples adição de uma "parte" social ao direito ambiental, caracterizando-se por uma forte conexão com o histórico-material e com o mundo e parte do pressuposto da diversidade, que falta às demais áreas do Direito.

Em verdade e nesse momento, concordando com os positivistas em relação às fontes sociais do Direito, o socioambiental apresenta uma crítica do direito estatal, partindo também dos direitos existentes para além do Estado, direitos estes que são coletivos, sendo que sua incorporação nas cartas constitucionais do Brasil e da América Latina tem decorrido da luta dos povos indígenas e tradicionais. Essas mesmas cartas constitucionais embasam um direito que 
foi constituído originalmente para negar esses mesmos direitos coletivos (SOUZA FILHO, 2017).

Do ponto de vista da ciência do direito, constituída com base em concepções próprias da modernidade, esses direitos coletivos reconhecidos nas constituições da América Latina, pelo movimento que se convencionou chamar constitucionalismo latino-americano, representaram uma nueva mirada epistemológica à compreensão da própria sociedade, ao expor o caminho de autoaniquilação que estava sendo respaldado pelos sistemas jurídicos nacionais. Para a compreensão dessa nova perspectiva, é necessário que o Direito seja desencastelado e parta para o diálogo com outras áreas do saber, tendo em vista sua incompatibilidade com a realidade material e sua impossibilidade de criar realidades.

A Antropologia, a Sociologia, a Economia Política e a Geografia, por exemplo, são essenciais à compreensão de um novo mundo possível, construído a partir da visão do outro. Necessário destacar também a importância da História para a construção de uma ciência e de uma prática educativa que se aperfeiçoe a partir de si. Sendo necessário o diálogo com outras disciplinas, novas metodologias de ensino-aprendizagem também são possíveis, de forma a fugir da educação bancária e contemplar a diversidade de pontos de vista existentes de uma forma crítica. A metodologia ativa da espiral construtivista (CESARIO et al., 2018) é, dentre as metodologias ativas (PAIVA et al., 2016), aquela que apresenta maiores facilidades de abordagens interdisciplinares e a multiplicação dos pontos de vista para análise (LIMA, 2017).

Nesse sentido, a partir de uma abordagem interdisciplinar, o direito socioambiental faz com que o direito ambiental confronte a sua própria realidade, de espoliação e violência, que é a mesma das outras áreas do direito estatal e também confronte a própria estrutura da sociedade

de risco, que questiona a responsabilidade organizada e o estado de aparente normalidade. É a expressão de um "saber ambiental” (LEFF, 2004) necessário para que transformações sejam realizadas e, quem sabe, possa-se construir algo a fim de evitar as catástrofes que pairam sobre a humanidade.

\section{CONSIDERAÇÕES FINAIS}

O direito moderno estatal abraçou para si o dever de garantir a expansão do modo de produção capitalista que, em decorrência de sua própria dinâmica, é violento e destrutivo. Se se deve transformar o direito, a fim de que ele possa ser um instrumento de mudanças 


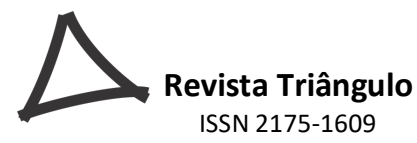

necessárias na sociedade, é preciso também mudar a reprodução enquanto ciência. Ou seja, o seu ensino também deve ser modificado, mediante o abandono do ensino bancário e a adoção de uma postura crítica e de metodologias de ensino que tornem possível reflexões. No contexto de sociedade de risco e crise ecológica em curso, é imperiosa a necessidade de uma prática educativa que contemple a abordagem interdisciplinar do direito, para que a compreensão do mundo seja possível e, consequentemente, uma crítica capaz de transformá-lo em lar de sociedades mais justas e iguais, com respeito mútuo.

\section{REFERÊNCIAS}

BECK, U. A sociedade do risco: em busca de uma nova modernidade. São Paulo: Editora 34, 2010.

BECK, U. La sociedad del riesgo global. España: Siglo Veintiuno, 2002.

BRASIL. Lei n. 6.938, de 31 de agosto de 1981. Dispõe sobre a Política Nacional do Meio Ambiente, seus fins e mecanismos de formulação e aplicação, e dá outras providências.

Brasília: Diário Oficial da União, 02 set. 1981. Disponível em: http://www.planalto.gov.br/ccivil_03/Leis/L6938.htm. Acesso em: 18 out. 2019.

BRASIL. Ministério da Educação. Conselho Nacional de Educação. Câmara de Educação Superior. Resolução n. 5, de 17 de dezembro de 2018. Institui as Diretrizes Curriculares Nacionais do curso de graduação em Direito e dá outras providências. Brasília: Diário Oficial da União, 18 dez. 2018. Disponível em:

http://portal.mec.gov.br/index.php?option=com docman\&view=download\&alias=104111rces005-18\&category_slug=dezembro-2018-pdf\&Itemid=30192 . Acesso em: 15 jan. 2020.

CALEIRO, M. M.; SOUZA FILHO, C. F. M. Os Guarani e o direito ao centro da terra. 2018. 257f. Tese (Doutorado em Direito Econômico e Socioambiental) - Pontifícia Universidade Católica do Paraná, Curitiba, 2018.

CALEIRO, M.; WANDSCHEER, C. B. Sistemas jurídicos originários: entre o plural e o diverso. In: MARÉS, C. F.; TARREGA, M. C. V. B.; SANTAMARIA, R. A.; CALEIRO, M. (org.). Estados e povos na América Latina plural. 1. ed. Goiânia: Editora da PUC Goiás, 2016. p. 151-177.

CAPRA, F. A teia da vida: uma nova compreensão científica dos sistemas vivos. Tradução: Newton Roberval Eichemberg. São Paulo: Cultrix, 2006.

CAPRA, F. As conexões ocultas. São Paulo: Cultrix, 2006.

CESARIO, R. R. et al. Espiral construtivista na pós-graduação: um relato de caso. PBL for the next generation - Blending active learning, technology and social justice. Santa Clara, Califórnia, USA, fevereiro de 2018. Disponível em: http://pbl2018.panpbl.org/wpcontent/uploads/2018/02/Espiral-Construtivista-na-Posgraduação.pdf Acesso em: 8 out. 2019.

CORNETTA, A. A financeirização do clima: uma abordagem geográfica do mercado de carbono e suas escalas de operação. São Paulo: Annablume; Fapesp, 2012. 
DIEGUES, A. C. et al. (org.). Os saberes tradicionais e a biodiversidade no Brasil. São Paulo: NUPAUB/USP, PROBIO/MMA e CNPq, 1999/2000. p. 31-32.

DIEGUES, A. C. S. O mito moderno da natureza intocada. São Paulo: Hucitec, 2001.

DWORKIN, R. M. O império do direito. 3. ed. São Paulo: Martins Fontes, 2014.

FERREIRA, H. S. A dimensão ambiental da teoria da sociedade de risco. In: FERREIRA, H. S.; FREITAS, C. O. A. (org.). Direito socioambiental e sustentabilidade: Estados, Sociedade e Meio Ambiente. Curitiba: Letra da Lei, 2016. p. 108-158.

FOSTER, J. B. O conceito de natureza em Marx: materialismo e natureza. 3. ed. Rio de Janeiro: Civilização Brasileira, 2011.

FREIRE, P. Pedagogia da autonomia. São Paulo: Paz e Terra, 2002. E-book. http://www.apeoesp.org.br/sistema/ck/files/4\%20Freire P \%20Pedagogia\%20da\%20autonomia.pdf. Acesso em: 20 out. 2019

HART, H. L. A. O conceito de direito. 6. ed. Lisboa: Fundação Calouste Gulbenkian, 2011. KELSEN, H. Teoria pura do direito. 8. ed. São Paulo: WMF Martins Fontes, 2009.

LEFF, E. Saber ambiental: sustentabilidade, racionalidade, complexidade, poder. 3. ed. rev. e aum. Petrópolis: Vozes, 2004.

LIMA, V. V. Espiral construtivista: uma metodologia ativa de ensino-aprendizagem.

Interface, Botucatu, v. 21, n. 61, p. 421-434, junho 2017. Disponível em:

http://www.scielo.br/scielo.php?script $=$ sci arttext\&pid=S1414-

32832017000200421\&lng=en\&nrm=iso. Acesso em: 13 out. 2019.

LÖWY, M. Ecologia e socialismo. São Paulo: Cortez, 2005.

LYRA FILHO, R. O que é direito? São Paulo: Brasiliense, 2012.

MACHADO, P. A. L. Direito ambiental brasileiro. 23. ed. São Paulo: Malheiros Editores, 2015.

MANDEL, E. O capitalismo tardio. São Paulo: Abril Cultural, 1982. p. 333-334.

MESZÁROS, I. A crise estrutural do capital. São Paulo: Boitempo, 2011.

PAIVA, M. R. F.; PARENTE, J. R. F.; BRANDÃO, I. R.; QUEIROZ, A. H. B. Metodologias ativas de ensino aprendizagem: revisão integrativa. SANARE, Sobral, v. 15, n. 2, p. 145-153, jun./dez.2016. Disponível em: https://sanare.emnuvens.com.br/sanare/article/view/1049/595. Acesso em: 8 out. 2019.

PERALTA, C. E. Reforma fiscal verde e desenvolvimento sustentável: tributação ambiental no Brasil. Perspectivas. In: CARLI, A. A.; COSTA, L. A.; RIBEIRO, R. L. (org.).

Tributação e sustentabilidade ambiental. Rio de Janeiro: Editora FGV, 2015.

SILVA, D. A. Tributos verdes: proteção ambiental ou uma nova roupagem para antigas finalidades? Disponível em:

http://www.cidp.pt/publicacoes/revistas/ridb/2012/08/2012_08_4993_5023.pdf. Acesso em: 18 out. 2019.

SILVEIRA, A. F. Impactos socioambientais em Açailândia, Maranhão: a atuação do estado para viabilizar projetos de desenvolvimento na Amazônia. 2019. [238] p. Dissertação (Mestrado) - Pontifícia Universidade Católica do Paraná, Curitiba, 2019. Disponível em: 
http://www.biblioteca.pucpr.br/pergamum/biblioteca/img.php?arquivo=/00007c/00007c1f.pdf Acesso em: 11 set. 2019.

SOUZA FILHO, C. F. M. A função social da terra. Porto Alegre: Sergio Antonio Fabris Editor, 2003.

SOUZA FILHO, C. F. M. Palestra no XIV Congresso Brasileiro do Magistério Superior de Direito Ambiental, Vitória, 2016. Disponível em: http://videos.ufes.br/video/0_1lhgk4nl. Acesso em: 17 out. 2019.

SOUZA FILHO, C. F. M. de. A essência socioambiental do constitucionalismo latinoamericano. Revista da Faculdade de Direito da Universidade Federal de Goiás, Goiânia, v. 41, n. 1, p. 197-215, jan./jun. 2017.

TIBLE, J. Marx selvagem. São Paulo: Annablume, 2013.

TUPIASSU, L. V. C. Tributação ambiental: a utilização de instrumentos econômicos e fiscais na implementação ao meio ambiente saudável. Rio de Janeiro: Renovar, 2006.

WALZER, M. Da tolerância. Tradução de Almiro Pisetta. São Paulo: Martins Fontes, 1999.

WOOD, E. M. As origens agrárias do capitalismo. Revista Crítica Marxista, São Paulo, n. 10, 2000. 12-30. Disponível em:

https://www.ifch.unicamp.br/criticamarxista/arquivos_biblioteca/artigo6612_merged.pdf. Acesso em: 25 out. 2019.

WOOD, E. M. O império do capital. São Paulo: Boitempo, 2014. 